\title{
A laminated tufa carbonate from the mid Holocene of the Qilian Mountains and its potential for palaeoclimate inferences
}

\author{
1 Institute of Geological Sciences, Freie Universität Berlin, Malteserstr. 74-100, 12249 Berlin, Germany. E-mail: smischke@zedat.fu-berlin.de \\ 2 Lanzhou University, Centre for Arid Environment and Paleoclimate Research, Gansu, 730000, China.
}

A mid-Holocene tufa section at 3,815 $m$ altitude in the Qilian Mountains at the northeastern margin of the Tibetan Plateau was tested as a possibly important new climate archive. The tufa carbonate displays a distinct alternation of white and dark layers most probably representing annually deposited sparry and microgranular calcite which is formed during the warm and relatively wet summer and the drier and cooler spring and autumn season with an interruption of tufa formation during the freezing period. The $\delta^{18} \mathrm{O}$ record of the tufa site comprises probably 357 years of annually deposited carbonate about 4,000 years before present, which indicates the prevalence of wetter climatic conditions in comparison to the present-day situation. This inference is confirmed by palynological data and lake-level reconstructions from a number of sites in the northern foreland of the Qilian Mountains, highlighting the large potential of longer tufa sequences for high-resolution palaeoclimate studies in the future.

\section{Introduction}

Continuously formed carbonate sequences were recognized as valuable sources of palaeoclimate information in recent years benefiting from steadily improving dating techniques and an increasing temporal resolution of the sampled records. In addition to classical climate archives such as ice cores, marine or lake sediments and loess sections, stable isotope records from speleothems provided new insights into the climatic evolution on the continents (e.g., Bar-Matthews et al., 1999; Wang et al., 2001; Fleitmann et al., 2003). Besides these cave deposits, tufa carbonates formed from spring or stream waters have been used as climate archives (e.g., Pentecost, 1995; Matsuoka et al., 2001; Minissale et al., 2002; Soligo et al., 2002; Horvatinčić, 2003). Depending on the degree of seasonality at a certain site, tufa carbonates may occur as annually laminated carbonate formations which have the potential to provide climate records with annual or even sub-annual resolution. The lamination often results from the seasonal variation of a number of parameters such as water saturation with respect to $\mathrm{CaCO}_{3}$, temperature, evaporation, discharge volume of springs and/or the biological productivity. Although sparite-micrite couplets regarded as annually deposited tufa carbonates were described from a number of sites all over the world (e.g., Chafetz et al., 1991; Benson, 1994; Pentecost, 1995; Matsuoka et al., 2001; Liu et al., 2006), few laminated tufa carbonates have been tested in the course of palaeoclimate studies in China (Kano et al., 2004). This paper discusses the potential for palaeoclimate inferences of a laminated tufa carbonate section from the Qilian Mountains.

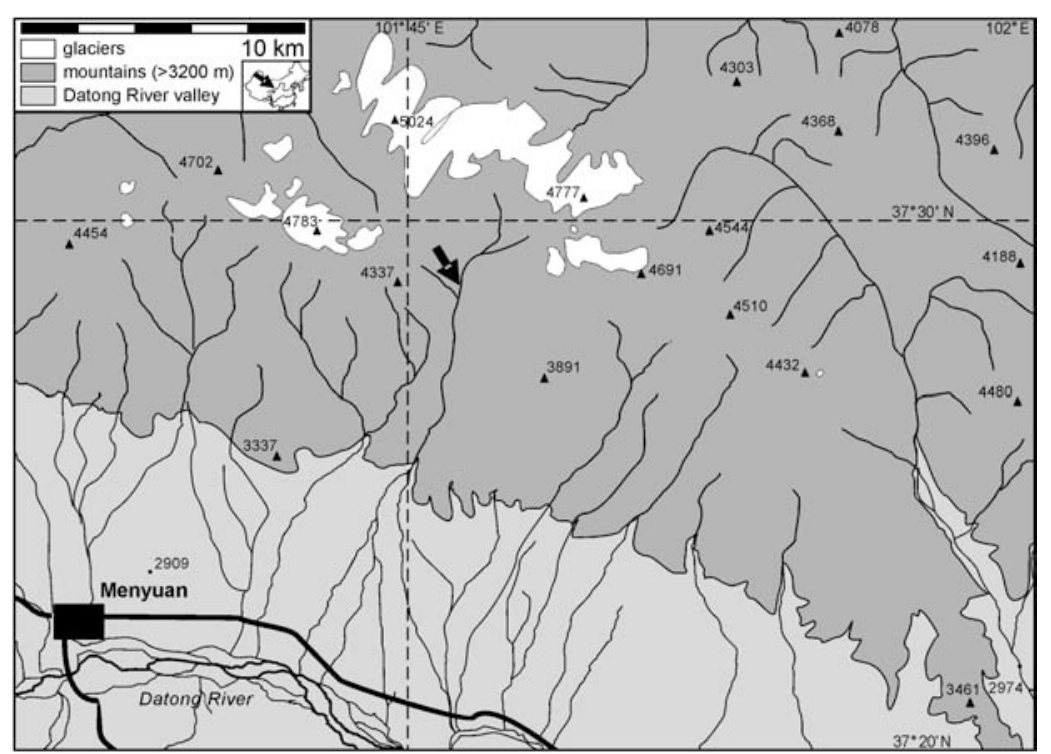

Figure 1 Position of the tufa section in the Qilian Mountains near Menyuan (arrow). Inset: general position.

\section{Study area}

The investigated tufa carbonate section is situated at $37^{\circ} 41^{\prime} \mathrm{N}$ and $101^{\circ} 27^{\prime} \mathrm{E}$ in the Lenglong Ling range of the eastern Qilian Mountains. Carbonate formation occurs on the western bank of a stream in a glacially eroded side valley of the Datong River valley at $3,815 \mathrm{~m}$ above sea level (Figure 1). Meteorological data for the adjacent town of Menyuan indicate a strongly seasonal climate, both in terms of temperature and precipitation (Figure 2). The mean annual temperature for Menyuan is $0.6^{\circ} \mathrm{C}$ and the mean annual precipitation is $520 \mathrm{~mm}$ which is mostly falling between May and September. Based on the temperature-altitude gradient of $-0.54^{\circ} \mathrm{C} / 100 \mathrm{~m}$ given by Böhner (1994), a mean annual temperature of about $-5^{\circ} \mathrm{C}$ is estimated for the

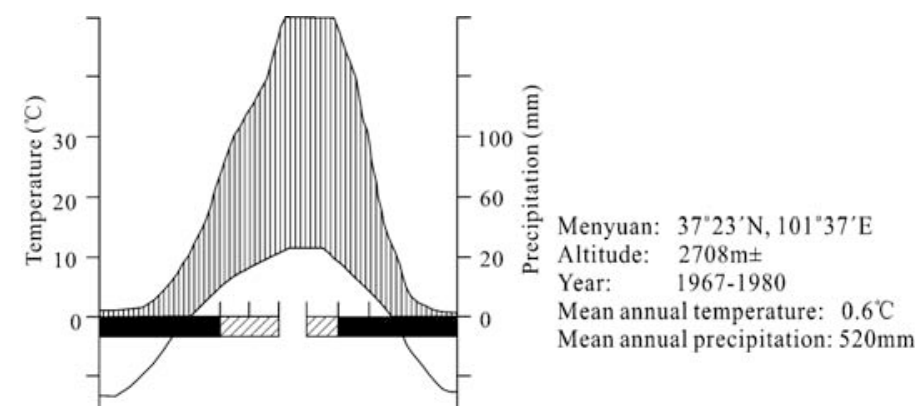

Figure 2 Climate diagram after Walter and Lieth (1960-1967) for Menyuan (Data from the Meteorological Survey of China). 
spring tufa site. Ordovician marine carbonate rocks are exposed in the vicinity of the tufa site (Geological map of the Tibetan Plateau, 1980).

\section{Material and methods}

Carbonate precipitation at the tufa site led to the formation of a flat terrace-like area on the stream bank. Fluvial erosion has cut into the tufa formation, creating a steep slope. The sampled tufa carbonate represents a $3.9 \mathrm{~m}$ high section that was exposed at a position where a large block was broken from the main tufa body by lateral fluvial erosion. The tufa carbonate at the top of this section was not actively forming. Two parallel vertical cuts about $5 \mathrm{~cm}$ apart were made into the carbonate rock using a gasoline-driven cutter, and the material between the cuts was sampled using a hammer and chisel. Six continuous sub-sections within a distance of $5 \mathrm{~m}$ were sampled at different accessible places on the large tufa block, and were correlated in the field using distinct parallel-stretching marker layers. It was not possible to sample a longer continuous section including the most recently formed tufa during the sampling period in September 2005, due to the relatively heavy spring discharge after continuous rainfall in previous days. As well, overhanging slopes at the steep streamward edge of the tufa deposits were considered unsafe.

The unweathered sides of the tufa samples were cut and polished to planar surfaces in the laboratory and then used for stable isotope subsampling. A total of 336 samples were taken, predominantly from the white layers, at an average distance of about $1.2 \mathrm{~cm}$ using a Wabeco CC-F 1200 E milling machine and a drill with $1 \mathrm{~mm}$ diameter. An additional high-resolution set of 20 samples was taken from a unit of $3 \mathrm{~cm}$ thickness displaying four distinct white-dark couplets from the middle of the section. Five samples of modern tufa carbonate were collected for stable isotope analyses from five different small streams a few metres away from the springs. Growing algae in the streams was abundant and did not show signs of carbonate encrustation. The water temperature of the streams ranged from $12.5^{\circ} \mathrm{C}$ to $13.9^{\circ} \mathrm{C}$ on the day of sampling (September 20, 2005). According to hourly readings of the water temperature of the largest spring between 11 am and $6 \mathrm{pm}$, the spring water temperature was almost stable with values between 12.4 and $12.5^{\circ} \mathrm{C}$. In addition to fossil and Recent tufa samples, five limestone samples were collected from the basement rocks up to $100 \mathrm{~m}$ above the tufa-precipitating springs.

Carbonate powders were reacted for stable isotope analysis with $100 \%$ phosphoric acid (density $>1.9$, Wachter and Hayes, 1985) at $75^{\circ} \mathrm{C}$ using a Kiel III online carbonate preparation line connected to a ThermoFinnigan 252 masspectrometer at the Institute of Geology and Mineralogy, University of Erlangen. All values are reported in per mil relative to $\mathrm{V}-\mathrm{PDB}$ by assigning a $\delta^{13} \mathrm{C}$ value of $1.95 \%$ and a $\delta^{13} \mathrm{C}$ value of $-2.20 \%$ o to NBS19. Reproducibility was checked by replicate analysis of laboratory standards and is better than $\pm 0.06 \%$ \% $(1 \sigma)$ for both $\delta^{13} \mathrm{C}$ and $\delta^{18} \mathrm{O}$ values.

Thin sections were prepared from the planar surfaces of the tufa samples that had been used for stable isotope subsampling. The thin sections, which show small holes as a result of the subsampling process, were used to count the white and dark tufa couplets and to characterize the depositional type of the tufa carbonate as 'regularly laminated' or 'reworked breccia-like tufa'.
The mineralogy of the tufa carbonate was assessed through X-ray diffraction analysis of three samples from 3.0, 2.0 and $1.0 \mathrm{~m}$ below the section top using a Philips PW $1050 \mathrm{X}$-ray spectrometer. The powdered samples were scanned from $10^{\circ}$ to $60^{\circ}$ using $\mathrm{Cu}-\mathrm{K} \alpha$ radiation.

$\mathrm{U}$ - and Th-series isotope measurements using multi-static multiple ion counting inductively coupled plasma mass spectrometry (MIC-ICP-MS) were carried out on eight samples at the GEOMAR Research Center for Marine Geosciences, Kiel, using a Finnigan MAT 262 RPQ2+ mass spectrometer according to Fietzke et al. (2005). A ${ }^{230} \mathrm{Th} /{ }^{232} \mathrm{Th}$ activity ratio of $0.6 \pm 0.2$ was used for the correction of detrital ${ }^{230} \mathrm{Th}$.

Spectral analysis of the $\delta^{18} \mathrm{O}$ and $\delta^{13} \mathrm{C}$ time series was carried out using the software package PAST - PAleontological STatistics (ver. 1.34; Hammer et al., 2001). Some of the annual layers have not been sampled for stable isotope analysis and artificial stable isotope data were produced for these layers as an average of the stable isotope values from the two neighbouring layers above and below.

\section{Results}

Calcite was observed as the only mineral species by X-ray diffraction analysis of three exemplary tufa samples. Thin section analysis revealed that almost the entire tufa section consists of 354 regular white-dark couplets. The thicker white layers of the tufa carbonate are characterised by radiating, fan-shaped bundles of sparry calcite crystals, whereas the thinner dark layers consist of microgranular calcite crystals within a cryptocrystalline matrix. Organic structures such as algae filaments or dust particles occur very rarely in the carbonate. The tufa fabric can be described as a dense sinter-like layered carbonate. Between 0.965 and $0.940 \mathrm{~m}$ below the top of the section, the regular white-dark couplets are replaced by irregular microgranular calcite crystals which do not show the typical layering feature. Between 1.185 and $1.150 \mathrm{~m}$ below the top and between 0.630 and $0.575 \mathrm{~m}$ below the top, lumps of larger sparry calcite crystals are irregularly spaced within micro- and cryptocrystalline calcite.

The U- and Th-series isotope measurements on eight tufa samples revealed ages of about 4,000 years (Table 1). All obtained ages are more or less identical within standard deviations (Figure 3 ).

Stable oxygen isotope values of 336 tufa samples from the section range between $-9.6 \%$ and $-7.1 \%$ (mean $-8.6 \%$, standard deviation $0.5 \% o$ ) and stable carbon isotopes between $4.5 \%$ and $11.6 \%$ (mean $6.9 \%$, standard deviation $1.3 \%$ ). The 20 additional highresolution samples from the middle of the section yielded stable oxygen isotope values between $-8.7 \%$ and $-7.7 \%$ and stable carbon isotope values between $6.6 \%$ and $9.9 \%$. Five modern tufa samples yielded $\delta^{18} \mathrm{O}$ values between $-8.2 \%$ and $-7.4 \%$ (mean $-7.7 \%$ ) and $\delta^{13} \mathrm{C}$ values between $6.5 \%$ and $7.7 \%$ (mean $7.2 \%$ ). Five limestone samples representing the bedrock geology in the neighbourhood of the tufa section have $\delta^{18} \mathrm{O}$ values between $-12.1 \%$ and $-9.1 \%$ (mean $-10.6 \%$ ) and $\delta^{13} \mathrm{C}$ values ranging from $1.3 \%$ to $2.6 \%$ (mean $2.0 \%$ ).

The $\delta^{18} \mathrm{O}$ values of the section show a slight increase from the base of the section and a sharp drop at about the white-dark couplet 60 (Figure 4). This pattern of relatively steady increases and relatively rapid drops of the $\delta^{18} \mathrm{O}$ values occurs another two times in the lower half of the section (with trend reversals around couplets 120

Table 1 Isotope data and ages of the tufa carbonate in the Qilian Mountains.

\begin{tabular}{|c|c|c|c|c|c|c|c|c|c|c|}
\hline Sample & $\begin{array}{l}\text { Depth } \\
\text { below } \\
\text { top }(\mathrm{m})\end{array}$ & ${ }^{238} \mathrm{U}$ (ppm) & ${ }^{232} \mathrm{Th}$ (ppb) & ${ }^{230 \mathrm{Th}}(\mathrm{ppt})$ & ${ }^{230} \mathrm{Th} /{ }^{232} \mathrm{Th}$ & ${ }^{238} \mathrm{U} /{ }^{232} \mathrm{TH}$ & ${ }^{230} \mathrm{Th} /{ }^{238} \mathrm{U}$ & ${ }^{230} \mathrm{Th}_{\text {excess }} f^{238} \mathrm{U}$ & ${ }^{234} U I^{238} U$ & Age (kyr) \\
\hline $1-1$ & 0.02 & $0.462 \pm 0.001$ & $7.71 \pm 0.07$ & $0.44 \pm 0.01$ & $10.63 \pm 0.26$ & $185.6 \pm 1.7$ & $0.057 \pm 0.001$ & $0.054 \pm 0.002$ & $1.270 \pm 0.006$ & $4.74 \pm 0.18$ \\
\hline $2-2$ & 0.53 & $0.388 \pm 0.001$ & $21.19 \pm 0.14$ & $0.33 \pm 0.01$ & $2.91 \pm 0.08$ & $56.7 \pm 0.4$ & $0.051 \pm 0.001$ & $0.041 \pm 0.004$ & $1.271 \pm 0.004$ & $3.55 \pm 0.35$ \\
\hline $2-5$ & 1.12 & $0.409 \pm 0.001$ & $94.49 \pm 0.39$ & $0.64 \pm 0.01$ & $1.26 \pm 0.02$ & $13.4 \pm 0.1$ & $0.094 \pm 0.002$ & $0.049 \pm 0.015$ & $1.263 \pm 0.003$ & $4.33 \pm 1.36$ \\
\hline $2-9$ & 1.68 & $0.375 \pm 0.001$ & $41.93 \pm 0.24$ & $0.41 \pm 0.01$ & $1.85 \pm 0.05$ & $27.7 \pm 0.2$ & $0.067 \pm 0.002$ & $0.045 \pm 0.007$ & $1.269 \pm 0.004$ & $3.94 \pm 0.67$ \\
\hline $3-7$ & 2.25 & $0.347 \pm 0.001$ & $13.30 \pm 0.07$ & $0.31 \pm 0.01$ & $4.32 \pm 0.12$ & $80.6 \pm 0.5$ & $0.054 \pm 0.001$ & $0.046 \pm 0.003$ & $1.265 \pm 0.005$ & $4.05 \pm 0.28$ \\
\hline $3-11$ & 2.73 & $0.416 \pm 0.001$ & $92.95 \pm 0.49$ & $0.64 \pm 0.02$ & $1.29 \pm 0.04$ & $13.9 \pm 0.1$ & $0.093 \pm 0.003$ & $0.050 \pm 0.015$ & $1.268 \pm 0.004$ & $4.39 \pm 1.33$ \\
\hline $6-4$ & 3.32 & $0.400 \pm 0.001$ & $36.94 \pm 0.18$ & $0.43 \pm 0.01$ & $2.17 \pm 0.05$ & $33.5 \pm 0.2$ & $0.065 \pm 0.001$ & $0.047 \pm 0.006$ & $1.274 \pm 0.003$ & $4.08 \pm 0.55$ \\
\hline $6-6-3$ & 3.83 & $0.430 \pm 0.001$ & $57.49 \pm 0.28$ & $0.52 \pm 0.01$ & $1.69 \pm 0.02$ & $23.1 \pm 0.1$ & $0.073 \pm 0.001$ & $0.047 \pm 0.009$ & $1.281 \pm 0.004$ & $4.09 \pm 0.78$ \\
\hline
\end{tabular}




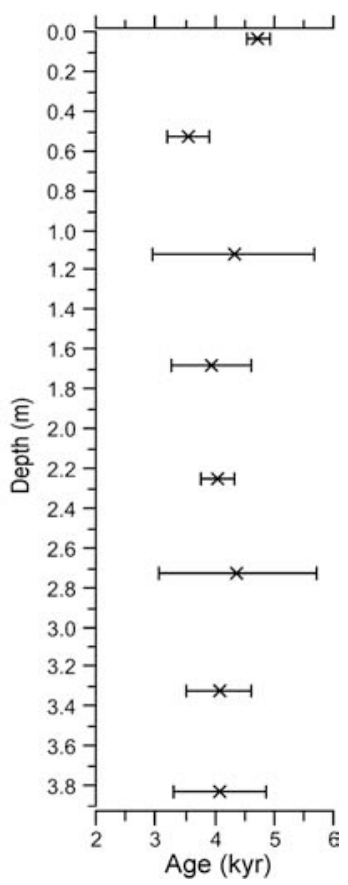

Figure 3 Age results plotted against depth below the top of the section. Crosses are mean ages. Horizontal bars represent one standard deviation.

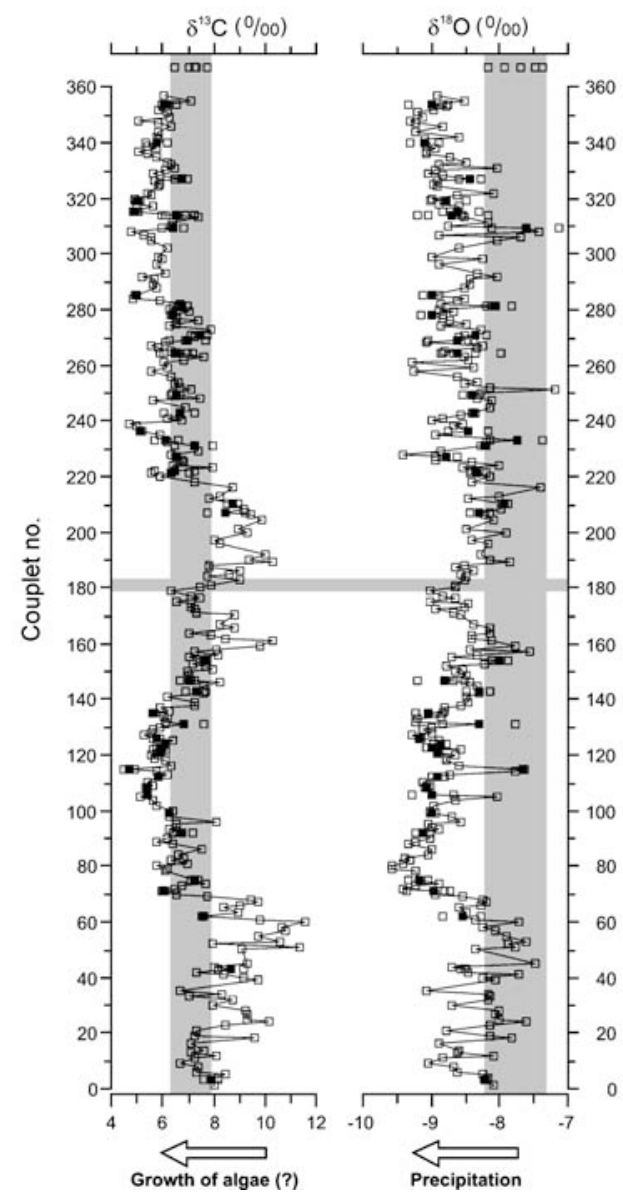

Figure 4 Stable isotope values of the investigated tufa section plotted against the numbers of the white-dark couplets regarded as annual layers. Empty boxes represent a single sample, filled boxes mark arithmetical means for a layer where two or more samples were measured. The samples at the top and the vertical grey bars indicate the stable isotope values of modern tufa samples. The horizontal grey bar shows the position of the high-resolution stable isotope analysis on four selected white-dark couplets (Figure 5).

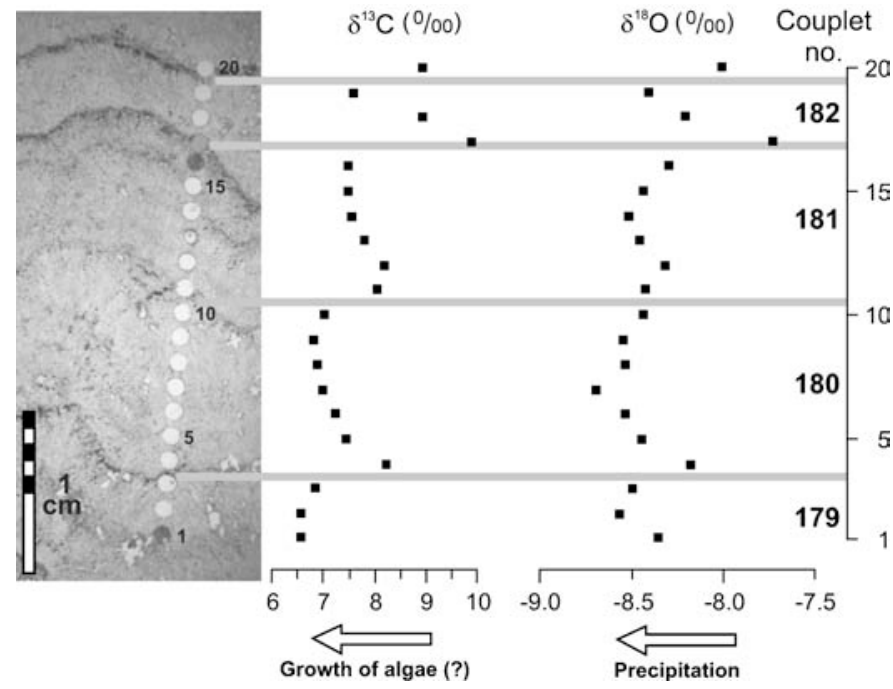

Figure 5 High-resolution stable-isotope data for a selected unit of four white-dark couplets 179,180,181 and 182 in the middle of the tufa section (see Figure 4 for position). Photo of thin section with 20 holes resulting from the collection of stable isotope samples in the left. The grey bars mark the positions of distinct dark layers.

and 160 ). In the upper half of the section, $\delta^{18} \mathrm{O}$ values show a more irregular pattern or a steady increase and following decrease near the top. The $\delta^{13} \mathrm{C}$ values increase near the base of the section followed by a continuous decrease with a minimum around couplet 110 . Above, $\delta^{13} \mathrm{C}$ values increase steadily again to reach a second maximum around couplet 200. After a relatively rapid drop around couplet $220, \delta^{13} \mathrm{C}$ values remain relatively constant in the upper part of the section. The correlation coefficient for the $\delta^{18} \mathrm{O}$ and $\delta^{13} \mathrm{C}$ values of the tufa section samples is 0.5 .

The $\delta^{18} \mathrm{O}$ values of the high-resolution samples from the middle of the section display low values in the middle part of the white layers (Figure 5). $\delta^{18} \mathrm{O}$ minima were recorded for the high-resolution samples $2,7,14$ and $19 . \delta^{18} \mathrm{O}$ maxima were measured for the darker layers or for the sample(s) immediately above the darker layers. Similarly, ${ }^{13} \mathrm{C}$ data display maxima at or slightly above the dark layers whereas $\delta^{13} \mathrm{C}$ data show decreasing values within the white layers always starting at the base (Figure 5). The correlation coefficient for the $\delta^{18} \mathrm{O}$ and $\delta^{13} \mathrm{C}$ values of the high-resolution samples is 0.9 .

The results of spectral analysis for the $\delta^{18} \mathrm{O}$ values are given in Figure 6, which shows four periods: 219 yrs, 129 yrs, 86 yrs and 52 yrs. For $\delta^{13} \mathrm{C}$ values, a single period of 178 yrs was detected by spectral analysis.

\section{Discussion}

\section{Annual nature of the white-dark couplets}

Considering the low winter temperatures at the tufa site, it has to be assumed that the spring discharge ceases during the freezing period. Mean monthly temperatures remain below $0^{\circ} \mathrm{C}$ between November and April at the meteorological station at Menyuan about $1,000 \mathrm{~m}$ below the tufa site (Figure 2). The break in spring discharge causes the regular alternation of white and dark layers, with white layers representing fast-growing calcite crystals and dark layers representing ceasing carbonate precipitation and the relatively increased incorporation of dust and organic particles. The white-dark tufa couplets were therefore regarded as annual layers.

We assume that the thicker white layers were formed during the warm summer season when carbonate precipitation may be at a maximum due to the higher air temperatures, greater degassing of $\mathrm{CO}_{2}$ in emerging groundwaters and stronger evaporation. The tufa fabric is 
dense and not porous, showing that algae were not effectively incorporated into the carbonate. Cooler temperatures in autumn and spring would then cause a slower precipitation of carbonate. Dust deposition is higher during the dry winter half year as a result of the monsoon climate and may contribute to the darker colour of the thinner layers, although dust particles of microscopic size were not frequently detected during the examination of the thin sections. Traces of decaying organic particles from algae and bacteria were probably incorporated into the newly formed tufa carbonate in the spring season after the end of the freezing period. This mechanism of tufa formation would be comparable to the deposition of layered tufa carbonate in the Huanglong Ravine in northwestern Sichuan (China), where the values for $\mathrm{HCO}_{3}{ }^{-}, \mathrm{Ca}^{2+}$ and $\mathrm{pH}$ in the water of the tufadepositing alpine stream are higher in summer than in winter, with water being supersaturated with respect to $\mathrm{CaCO}_{3}$ in summer and undersaturated in late autumn and early winter (Liu et al., 1995; Lu et al., 2000).

Alternatively, one could assume that the carbonate production decreases during the monsoon season as a result of the dilution of spring waters by abundant precipitation. The thicker white layers were formed then during the dry period before and after the summer monsoon season, a scenario described for well-laminated freshwater travertines from a much warmer and wetter site in SW China's Yunnan Province by Liu et al. (2006). The formation of the tufa carbonate in the Qilian Mountains probably differs from this mode, because we were unable to find any evidence for a winter break in the formation of the sparry large calcite crystals which form the white layers of the tufa carbonate.

Stable isotope analysis of samples from four white-dark couplets in the middle of the section revealed that the $\delta^{18} \mathrm{O}$ and $\delta^{13} \mathrm{C}$ values follow regular increases and decreases within each couplet (Figure 5). These regular cycles may be regarded as evidence for the annual nature of the white-dark couplets. The recurrent shifts in the stable isotope data obviously reflect the strong seasonal contrasts at the tufa site during a year's cycle (see discussion below).

\section{Timing of tufa formation}

The eight virtually identical age data indicate that the formation of the investigated tufa section took place in the later part of the mid Holocene informally regarded as the period 8,000 to 3,000 years BP here (Figure 3). The section of $3.9 \mathrm{~m}$ height was deposited within a relatively short time about 4,000 years ago. The relatively low number of 354 white-dark couplets, which does not include two horizons of irregularly spaced lumps of larger sparry calcite crystals within micro- and cryptocrystalline calcite and one horizon with irregular microgranular calcite crystals without the typical layering feature, corresponds well to the short timing of tufa formation indicated by the age results. The two 3.5 and $5.5 \mathrm{~cm}$ thick units with lumps of larger sparry calcite crystals irregularly distributed within microand cryptocrystalline calcite between 1.185 and $1.150 \mathrm{~m}$ and 0.630 and $0.575 \mathrm{~m}$ below the top respectively probably represent reworked breccia-like tufa. Reworked material in tufa-precipitating streams may result from the dislocation of soft freshly formed tufa (1) by the flowing water of the streams, (2) by heavy rainfall or hailstorm events, or (3) by earthquakes. A relatively rapid sedimentation of the reworked material is assumed and both units as well as one $2.5 \mathrm{~cm}$ thick layer of irregular microgranular calcite crystals which does not show the typical layering feature at $0.95 \mathrm{~m}$ below the top of the section were therefore treated similar to a one-year white-dark couplet in Figure 4 and in the spectral analysis. It can be inferred, that the investigated tufa section was formed about 4,000 years BP spanning around 360 years of carbonate formation. A mean deposition rate of $11 \mathrm{~mm} / \mathrm{a}$ can be calculated which is relatively high in comparison to other tufa carbonate sites although deposition rates of $40 \mathrm{~mm} / \mathrm{a}$ have been determined for tufa carbonate at exceptional places (Pazdur et al., 1988; Pentecost, 1995; Vermoere et al., 1999).

\section{Stable isotope systematics}

The $\delta^{18} \mathrm{O}$ values of tufa carbonate reflect both the isotopic composition of the ambient water at the time of deposition and temperature. Numerous studies of tufa carbonates have shown that the stable oxygen isotope composition of the carbonate is mainly controlled by changes in the $\delta^{18} \mathrm{O}$ values of meteoric waters (Andrews et al., 1993, 1997). In low to mid latitudinal settings, the isotopic ratio of precipitation is strongly anti-correlated with the amount of rainfall (Rozanski et al., 1993). This clear relationship between the amount of the mean annual precipitation and the $\delta^{18} \mathrm{O}$ values of precipitation $\left(\delta^{18} \mathrm{O}_{\text {prec }}\right)$ also was observed for the Tibetan Plateau. Meteorological stations with higher amounts of precipitation record lower $\delta^{18} \mathrm{O}_{\text {prec }}$ values and vice versa, reflecting the effect of evaporation-controlled aridity at the drier locations (Wei and Gasse, 1999; Zhang et al., 2002 , 2004). Thus, lower $\delta^{18} \mathrm{O}$ values of the monsoonal precipitation over the Tibetan Plateau indicate wetter conditions, whereas higher $\delta^{18} \mathrm{O}$ values are typical for drier conditions. Temperature, another parameter which controls the $\delta^{18} \mathrm{O}$ values of precipitated carbonate, has a minor effect on the $\delta^{18} \mathrm{O}$ values in precipitation over the Tibetan Plateau with lower $\delta^{18} \mathrm{O}_{\text {prec }}$ values indicating cooler conditions (Zhang et al., 2004).

Considering the described relationship between the amount of precipitation on the Tibetan Plateau and its stable isotope signature, the $\delta^{18} \mathrm{O}$ minima within the four white-dark couplets from the middle of the section (Figure 5) represent the wettest monsoon period in summer, whereas higher $\delta^{18} \mathrm{O}$ values indicate the dry winter half year. Assuming that tufa formation ceases during the freezing period, the high $\delta^{18} \mathrm{O}$ values represent the autumn and spring periods. The $\delta^{18} \mathrm{O}$ minima occur in the middle of the white layers and the maxima appear at or slightly above the dark layers, confirming the first interpretation of the thicker white layers to represent the summer season and of the thinner dark layers to represent the drier autumn and spring periods.

The $\delta^{13} \mathrm{C}$ values of tufa carbonate generally reflect the isotopic composition of the dissolved inorganic carbon (DIC). The DIC may be controlled by a number of factors: (1) soil-zone $\mathrm{CO}_{2},(2)$ atmospheric $\mathrm{CO}_{2}$, (3) aquifer rock dissolution, (4) removal of ${ }^{12} \mathrm{C}$ by photosynthetic activity of micro-organisms such as cyanobacteria and (5) degassing of ${ }^{13} \mathrm{C}$-depleted $\mathrm{CO}_{2}$ from the spring water. Considering the high $\delta^{13} \mathrm{C}$ values with a mean of about $7 \%$, a straightforward explanation for the $\delta^{13} \mathrm{C}$ values of the tufa carbonate from the Qilian Mountains cannot be given. The high $\delta^{13} \mathrm{C}$ values obtained by our

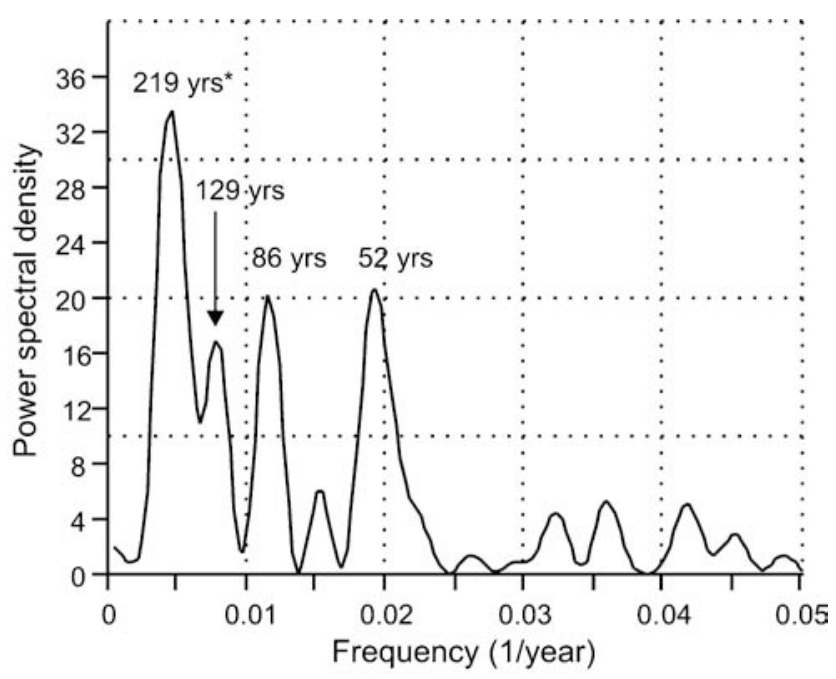

Figure 6 Dominant periods for the $\delta^{18} \mathrm{O}$ values of the tufa section revealed by spectral analysis using the software package PAST (Hammer et al., 2001). The value of 219 yrs marked by an asterisk (*) is clearly too long to provide a meaningful period in consideration of the studied duration of probably 357 yrs. 
study are in clear contrast to the typically much lower $\delta^{13} \mathrm{C}$ values of tufa carbonates in well-vegetated regions which usually have $\delta^{13} \mathrm{C}$ values between -12 and $-2 \%$, reflecting the respired soil $\mathrm{CO}_{2}$ with a $\delta^{13} \mathrm{C}$ of about $-20 \%$ (Pentecost, 1995). Soil-zone $\mathrm{CO}_{2}$ is probably not playing a major role as driving force which determines the $\delta^{13} \mathrm{C}$ values of the tufa carbonate investigated here due to the sparse or lacking vegetation in the high alpine environment. The $\delta^{13} \mathrm{C}$ values are also higher than the values which would be expected if calcite precipitation took place under isotopic equilibrium with atmospheric $\mathrm{CO}_{2}$. Atmospheric $\mathrm{CO}_{2}$ has a $\delta^{13} \mathrm{C}$ of about -6 to $-7 \%$ and calcite precipitation from waters in carbon isotopic equilibrium with atmospheric $\mathrm{CO}_{2}$ would lead to $\delta^{13} \mathrm{C}$ values between $1 \%$ and $4 \%$ o (Keeling, 1960; Cerling, 1984). In contrast to the tufa site in the Qilian Mountains, the early Holocene carbonate precipitates at Basköy (Turkey) were probably formed in equilibrium with atmospheric $\mathrm{CO}_{2}$ (Vermoere et al., 1999) as well as the modern tufa deposits in the upper part of the Huanglong Ravine, northwestern Sichuan, which have a mean $\delta^{13} \mathrm{C}$ of about $4 \%$ (Liu et al., 1995). The $\delta^{13} \mathrm{C}$ values of the tufa site in the Qilian Mountains are not reflecting the carbonaceous source rocks in the surroundings of the spring which have significantly lower $\delta^{13} \mathrm{C}$ values between $1.3 \%$ and $2.6 \%$. The relatively high $\delta^{13} \mathrm{C}$ values of the tufa deposits from the Qilian Mountains could be possibly explained by the removal of ${ }^{12} \mathrm{C}$ resulting from the photosynthetic activity of micro-organisms such as Cyanobacteria, Chlorophyta, Crysophyta and Baccilariophyta. Green and brown 'algae films' were observed in the streams at the tufa site. An additional process which may have contributed to the ${ }^{13} \mathrm{C}$-enrichment of the tufa carbonates is the degassing of ${ }^{13} \mathrm{C}$ depleted $\mathrm{CO}_{2}$ from the spring water as a result of the decrease of the $\mathrm{CO}_{2}$ partial pressure at the resurgence.

The $\delta^{13} \mathrm{C}$ values of the four white-dark couplets from the middle of the section display maxima at the dark layers or at the sample(s) directly above the dark layers (Figure 5). The stable carbon isotopes seem to decrease steadily from the lower part of the white layers towards the top where an abrupt rise over the thin dark layer occurs again. If our assignment of the thick white layers to the summer seasons and of the dark layers to autumn and spring periods is correct, the pattern of the $\delta^{13} \mathrm{C}$ values is not easily interpreted. The corresponding occurrences of the $\delta^{18} \mathrm{O}$ and $\delta^{13} \mathrm{C}$ maxima suggest that climatic parameters such as precipitation and/or temperature are the driving agents which control the $\delta^{13} \mathrm{C}$ values, in contrast, the $\delta^{18} \mathrm{O}$ and $\delta^{13} \mathrm{C}$ minima seem to occur at different times within the year's cycle (Figure 5). If the $\delta^{18} \mathrm{O}$ minima reflect the times of peak precipitation during the summer season, the $\delta^{13} \mathrm{C}$ minima occur probably in autumn. This observation implies that the stable carbon isotopes are not closely linked to temperature and/or precipitation which are both at maximum in summer. Several processes are discussed to explain the characteristic $\delta^{13} \mathrm{C}$ cycles.

The carbon isotope values could be related to the amount of spring water. In summer, the spring water discharge is probably largest as a result of the pronounced monsoonal precipitation peak in July and August (Figure 2). The preferential uptake of ${ }^{12} \mathrm{C}$ by algae probably does not result in a significant enrichment of ${ }^{13} \mathrm{C}$ in the tufa carbonates due to the large quantities of emerging waters in the wet summer months. In contrast, the removal of ${ }^{12} \mathrm{C}$ through the photosynthetic activity of micro-organisms may result in higher $\delta^{13} \mathrm{C}$ values of tufa carbonate during times of low water discharge, i.e. during the dry season before and following the freezing period. However, we cannot explain the occurrence of the $\delta^{13} \mathrm{C}$ maxima which probably occur during the spring when the photosynthetic activity of micro-organisms is probably low due to their lower abundance immediately after the freezing period.

Although the catchment of the tufa carbonate precipitating streams comprises bare rocks and scree slopes without visible vegetation, lichens and mosses may possibly play a significant role in influencing the soil-zone $\mathrm{CO}_{2}$ during the warm season. The low $\delta^{13} \mathrm{C}$ values of the tufa carbonate during summer and autumn (i.e. in the upper half of the white layers, Figure 5) possibly reflect the higher contribution of respired soil $\mathrm{CO}_{2}$ to the dissolved inorganic carbon of the ground water. The $\delta^{13} \mathrm{C}$ values increase in late autumn and especially in spring, when the photosynthetic activity of lichens and mosses slows down as a result of the low air temperatures. This scenario provides an explanation for the occurrence of the $\delta^{13} \mathrm{C}$ maxima in the assumed spring season. However, it remains doubtful that the available biomass is sufficiently large to exert a significant influence on the $\delta^{13} \mathrm{C}$ pattern of the tufa carbonate.

Alternatively, the amount of incorporated microbial material into the tufa carbonate during a year's cycle could explain the $\delta^{13} \mathrm{C}$ maxima in spring and the following $\delta^{13} \mathrm{C}$ decrease over the summer period. Micro-organisms such as algae are probably not abundant in spring after the freezing period but will become more abundant gradually during the warm season. As more and more algae grow during the warm season in the streams, more and more ${ }^{12} \mathrm{C}$-enriched algae remains possibly become incorporated into the tufa carbonate, causing a gradual decrease of the $\delta^{13} \mathrm{C}$ values over the growing period. This process could explain the occurrence of the $\delta^{13} \mathrm{C}$ maxima in the assumed spring season and the gradual decrease of the $\delta^{13} \mathrm{C}$ values over the warm summer half year. Further more, this process could explain the time lag between the $\delta^{18} \mathrm{O}$ and the $\delta^{13} \mathrm{C}$ minima by the time delay between precipitation (and temperature) maxima in July and August on the one side and the response of micro-organisms to optimal growing conditions and the incorporation of organic material into the tufa carbonate on the other side.

However, detailed analyses of present-day tufa formation are necessary to clarify which processes of those described above or of other processes not considered here may play a major role in controlling the $\delta^{13} \mathrm{C}$ trends in the tufa carbonate from the Qilian Mountains. At the present state of research, we may use the third interpretation as a tentative model to explain the pattern of the $\delta^{13} \mathrm{C}$ data (Figures 4 and 5).

\section{Palaeoclimate inferences}

The majority of the $\delta^{18} \mathrm{O}$ values of the tufa section are relatively low in comparison to the values which were measured on freshly formed tufa samples (Figure 4). This deviation indicates climatic differences between the late mid-Holocene and the present-day climatic conditions in the eastern Qilian Mountains. Based on the observation that the present-day amount of precipitation on the Tibetan Plateau is negatively correlated with the $\delta^{18} \mathrm{O}$ signatures of precipitation (Wei and Gasse, 1999; Zhang et al., 2002, 2004), wetter conditions in the Qilian Mountains can be inferred about 4,000 yrs BP in comparison to the present day. This interpretation is confirmed by palynological data from Holocene lake records which indicate that wetter conditions prevailed in the northern foreland of the Qilian Mountains and in Mongolia about 4,000 yrs BP (see discussion below). The fluctuations of the $\delta^{18} \mathrm{O}$ values from the mid-Holocene tufa site may be interpreted to indicate slight precipitation changes over the observed period of about 360 years. Relatively high $\delta^{18} \mathrm{O}$ values near the base and in the upper part of the section suggest only slightly wetter or similarly dry conditions as at present, whereas significantly wetter periods were indicated by low $\delta^{18} \mathrm{O}$ values.

The $\delta^{13} \mathrm{C}$ values of the tufa section are comparable to the values measured on freshly formed tufa carbonate (Figure 4) and therefore do not allow the inference of significant differences in the conditions controlling the stable carbon isotope composition of the tufa carbonate. As discussed above, a straightforward explanation for the remarkable fluctuations in the $\delta^{13} \mathrm{C}$ values of the mid-Holocene tufa carbonate cannot be given. The $\delta^{13} \mathrm{C}$ fluctuations of the investigated tufa section might be interpreted in terms of temperature-governed algae growth and incorporation of ${ }^{12} \mathrm{C}$-enriched organic material into the tufa carbonate and similarly ${ }^{12} \mathrm{C}$-enriched soil-zone $\mathrm{CO}_{2}$ produced by lichens and mosses. However, detailed studies are necessary to improve the understanding of the $\delta^{13} \mathrm{C}$ systematics of tufa formation in the Qilian Mountains.

Wetter conditions in the Qilian Mountains inferred from the comparison of $\delta^{18} \mathrm{O}$ values of fossil and recently formed tufa carbonate may have possibly altered the overall conditions of tufa for- 
mation to some degree in comparison to the present. Wetter conditions are possibly related to a longer period of precipitation, a longer period of spring discharge and to a higher flow rate possibly resulting in an enhanced formation of sparry calcite during summer. Thus the white-dark couplets of the fossil tufa section are possibly thicker than white-dark couplets produced at present, although carbonate precipitation rates at possibly changed stream flow velocities and $\mathrm{CO}_{2}$-outgassing rates are difficult to assess. Unfortunately, a sequence of tufa carbonate from the last decades is not available to compare the thickness of fossil and sub-Recently formed white-dark tufa couplets. The photosynthetic activity of lichens and mosses was probably enhanced during the time of the tufa formation 4,000 yrs BP. ${ }^{12} \mathrm{C}$-enriched soil-zone $\mathrm{CO}_{2}$ may therefore have played a more important role than today. More respired soil $\mathrm{CO}_{2}$ may have led to an intensified dissolution of the exposed ancient carbonate rocks by the percolating groundwater. As the thickness of the annually precipitated white-dark couplets depends on a number of factors such as microbial growth, stream flow velocity and $\mathrm{CO}_{2}$-outgassing rates, we are unable to evaluate differences in carbonate precipitation 4,000 yrs BP and at present without a detailed study of sub-Recently and Recently formed tufa carbonate. However, the similarity between the $\delta^{13} \mathrm{C}$ values of the fossil and freshly formed tufa carbonate do not indicate that the wetter conditions 4,000 yrs BP have resulted in a significantly larger total biomass in the catchment of the tufa precipitating streams.

Based on spectral analysis of the $\delta^{18} \mathrm{O}$ values, four periods of 219 years, 129 years, 86 years and 52 years were detected. As the first value of 219 years revealed by PAST (Hammer et al., 2001) is clearly too large to represent a meaningful period, we cannot provide an explanation for the underlying mechanisms of the second and the last period. In contrast, the solar Gleissberg Cycle of about $80 \mathrm{yrs}$ may be possibly seen in the $\delta^{18} \mathrm{O}$ record of the tufa section (Gleissberg, 1958). However, longer time series would be necessary to confirm the relation of the observed $86-$ a periodicity in the $\delta^{18} \mathrm{O}$ record to this solar cycle. A period of 178 years was detected by spectral analysis of the $\delta^{13} \mathrm{C}$ values which is large in comparison to the duration of the observed time span of 357 years and which therefore cannot be regarded as a meaningful value. Any shorter-term periodicities in the $\delta^{13} \mathrm{C}$ values were not revealed by the analysis.

Evidence for a wetter climate in the Qilian Mountains about 4,000 yrs BP comes also from a number of lake sediment studies. Herzschuh et al. (2004) presented pollen data from a Holocene lake record in the northern foreland of the Qilian Mountains which indicate the most favourable (wettest) conditions between 5,400 yrs and 3,900 yrs BP for the entire record of the last 10,700 years. Wetter conditions ca. 4,000 yrs BP were also reconstructed on the basis of palynological data from the Mongolian lakes Dood Nuur, Gun Nuur and Lake Telmen (Dorofeyuk and Tarasov, 1998; Fowell et al., 2003).

The relatively straightforward inference of wetter conditions about 4,000 yrs BP based on palynological data is further confirmed by ostracod and geochemistry data of another lake sediment record from the Gobi Desert. Mischke et al. (2005) suggested that precipitation was more abundant between 5,100 yrs and 4,100 yrs BP in comparison to the present-day conditions in the upper catchment area of the Hei River in the Qilian Mountains although one has to be aware that a decrease in air temperature can affect the overall water budget of a lake in a similar way as a precipitation increase. A decrease in air temperature will contribute positively to the water budget of a lake through lowered evaporation and earlier condensation of water vapour. However, high lake levels at about 4,000 yrs $\mathrm{BP}$ were recorded from other mountain-rain fed lakes in the western, northern and eastern foreland of the Tibetan Plateau (Zhou et al., 1991; Wünnemann et al., 1998; Zhang et al., 1999, 2000; Shen et al., 2002; Chen et al., 2003) or in Mongolia also (Dorofeyuk and Tarasov, 1998; Peck et al., 2002). Thus, our inference of wetter conditions about 4,000 yrs BP from the investigated tufa record in the Qilian Mountains is confirmed by a number of palaeoclimate studies at nearby sites.

\section{Conclusion}

The potential of the laminated tufa carbonate in the Qilian Mountains for palaeoclimate studies with annual resolution has been demonstrated. A wetter climate about 4,000 yrs ago is inferred from the relatively low $\delta^{18} \mathrm{O}$ values of the mid-Holocene tufa compared to higher $\delta^{18} \mathrm{O}$ values of modern tufa carbonate. It was not possible to sample a longer continuous sequence without an appropriate drilling technique in the course of our study. However, longer sections which include freshly formed tufa at the top may provide detailed insights into the climatic evolution of the Qilian Mountains with a high temporal resolution.

\section{Acknowledgements}

We are indebted to Friederike Wetter and Mark Barlage for thinsection preparation and for the collection of samples for stable isotope analysis. In addition, we wish to thank Norm Catto for his thorough review. The research project was funded by the Deutsche Forschungsgemeinschaft (DFG).

\section{References}

Andrews, J.E., Riding, R., and Dennis, P.F., 1993, Stable isotopic compositions of Recent freshwater cyanobacterial carbonates from the British Isles: local and regional environmental controls. Sedimentology, v. 40, pp. 303-314.

Andrews, J.E., Riding, R., and Dennis, P.F., 1997, The stable isotope record of environmental and climatic signals in modern terrestrial microbial carbonates from Europe. Palaeogeography, Palaeoclimatology, Palaeoecology, v. 129, pp. 171-189.

Bar-Matthews, M., Ayalon, A., Kaufman, A., and Wasserburg, G.J., 1999, The Eastern Mediterranean paleoclimate as a reflection of regional events: Soreq cave, Israel. Earth and Planetary Science Letters, v. 166, pp. 85-95.

Benson, L., 1994, Carbonate deposition, Pyramid Lake subbasin, Nevada: 1. Sequence of formation and elevational distribution of carbonate deposits (Tufas). Palaeogeography, Palaeoclimatology, Palaeoecology, v. 109, pp. 55-87.

Böhner, J., 1994, Circulation and representativeness of precipitation and air temperature in the southeast of the Qinghai-Xizang Plateau. GeoJournal, v. 34, pp. 55-66.

Cerling, T.E., 1984, The stable isotopic composition of modern soil carbonate and its relationship to climate. Earth and Planetary Science Letters, v. 71, pp. 229-240.

Chafetz, H.S., Utech, N.M., and Fitzmaurice, S.P., 1991, Differences in the $\delta^{18} \mathrm{O}$ and $\delta^{13} \mathrm{C}$ signatures of seasonal laminae comprising travertine stromatolites. Journal of Sedimentary Petrology, v. 61, pp. 1015-1028.

Chen, C.A., Lan, H., Lou, J., and Chen, Y., 2003, The dry Holocene Megathermal in Inner Mongolia. Palaeogeography, Palaeoclimatology, Palaeoecology, v. 193, pp. 181-200.

Dorofeyuk, N.I., and Tarasov, P.E., 1998, Vegetation and lake levels in Northern Mongolia in the last 12,500 years as indicated by data of pollen and diatom analyses. Stratigraphy and Geological Correlation, v. 6, pp. 70-83.

Fietzke, J., Liebetrau, V., Eisenhauer, A., and Dullo, C., 2005, Determination of uranium isotope ratios by multi-static MIC-ICP-MS: method and implementation for precise U- and Th-series isotope measurements. Journal of Analytical Atomic Spectrometry, v. 20, pp. 395-401.

Fleitmann, D., Burns, S.J., Mudelsee, M., Neff, U., Kramers, J., Mangini, A., and Matter, A., 2003, Holocene forcing of the Indian Monsoon recorded in a stalagmite from southern Oman. Science, v. 300, pp. 1737-1739.

Fowell, S.J., Hansen, B.C.S., Peck, J.A., Khoshbayar, P., and Ganbold, E., 2003, Mid to late Holocene climate evolution of the Lake Telmen Basin, North Central Mongolia, based on palynological data. Quaternary Research, v. 59, pp. 353-363.

Geological map of the Tibetan Plateau (Ch'ing tsang kao ÿan ti chich ti t'u), 1980, 1:1,500000. Beijing, China National publishing industry trading corp.

Gleissberg, W., 1958, The eighty-year sunspot cycle. Journal of the British Astronomical Association, v. 68, pp. 148-152. 
Hammer, Ø., Harper, D.A.T., Ryan, P.D., 2001, PAST - Palaeontological Statistics. Software package for education and data analysis. Paleontologia Electronica, v. 4, pp. 1-9.

Herzschuh, U., Tarasov, P., Wünnemann, B., and Hartmann, K., 2004, Holocene vegetation and climate of the Alashan Plateau, NW China, reconstructed from pollen data. Palaeogeography, Palaeoclimatology, Palaeoecology, v. 211, pp. 1-17.

Horvatinč ić, N., Krajcar-Bronic, I., and Obelic, B., 2003, Differences in the ${ }^{14} \mathrm{C}$ age, $\delta^{13} \mathrm{C}$ and $\delta^{18} \mathrm{O}$ of Holocene tufa and speleothem in the Dinaric Karst. Palaeogeography, Palaeoclimatology, Palaeoecology, v. 193, pp. 139-157.

Kano, A., Liu, Z., Takashima, C., Kawai, T., and Hori, M., 2004, Paleoclimate analysis using tufa deposits - a case study in Niangziguan, Shanxi Province, China. Earth Science (Chikyu Kagaku),v. 58, pp. 305-316.

Keeling, C.D., 1960, The concentration and isotopic abundances of $\mathrm{CO}_{2}$ in the atmosphere. Tellus, v. 12, pp. 200-203.

Liu, Z., Li, H., You, C., Wan, N., and Sun, H., 2006, Thickness and stable isotopic characteristics of modern seasonal climate-controlled sub-annual travertine laminas in a travertine-depositing stream at Baishuitai, SW China: implications for paleoclimate reconstruction. Environmental Geology, v. 51, pp. 257-265.

Liu, Z., Svensson, U., Dreybrodt, W., Yuan, D., and Buhmann, D., 1995, Hydrodynamic control of inorganic calcite precipitation in Huanglong Ravine, China: Field measurements and theoretical prediction of deposition rates. Geochimica et Cosmochimica Acta, v. 59, pp. 3087-3097.

Lu, G., Zheng, C., Donahoe, R.J., and Lyons, W.B., 2000, Controlling processes in $\mathrm{CaCO}_{3}$ precipitating stream in Huanglong Natural Scenic District, Sichuan, China. Journal of Hydrology, v. 230, pp. 34-54.

Matsuoka, J., Kano, A., Watanabe, T., Sakai, S., and Seto, K., 2001, Seasonal variation of stable isotopic compositions recorded in a laminated tufa, SW Japan. Earth and Planetary Science Letters, v. 192, pp. 31-44.

Minissale, A., Kerrick, D.M., Magro, G., Murrell, M.T., Paladini, M., Rihs, S., Sturchio, N.C., Tassi, F., and Vaselli, O., 2002, Geochemistry of Quaternary travertines in the region north of Rome (Italy) : structural, hydrologic and paleoclimatic implications. Earth and Planetary Science Letters, v. 203, pp. 709-728.

Mischke, S., Demske, D., Wünnemann, B., and Schudack, M.E., 2005, Groundwater discharge to a Gobi desert lake during Mid and Late Holocene dry periods. Palaeogeography, Palaeoclimatology, Palaeoecology, v. 225, pp. 157-172.

Pazdur, A., Pazdur, M.F., Starkel, L., and Szulc, J., 1988, Stable isotopes of Holocene calcareous tufa in southern Poland as paleoclimatic indicators. Quaternary Research, v. 30, pp. 177-189.

Peck, J.A., Khosbayar, P., Fowell, S.J., Pearce, R.B., Ariunbileg, S., Hansen, B.C.S., and Soninkhishig, N., 2002, Mid to Late Holocene climate change in north central Mongolia as recorded in the sediments of lake Telmen. Palaeogeography, Palaeoclimatology, Palaeoecology, v. 183, pp. $135-153$.

Pentecost, A., 1995, The Quaternary travertine deposits of Europe and Asia Minor. Quaternary Science Reviews, v. 14, pp. 1005-1028.

Rozanski, K., Araguás-Araguás, L., and Gonfiantini, R., 1993, Isotopic patterns in modern global precipitation, in Swart, P. K., Lohmann, K. C., McKenzie, J., and Savin, S., eds, Climate change in continental isotopic records: Geophysical Monograph 78, American Geophysical Union, Washington, pp. 1-36.

Shen, J., Matsumoto, R., Wang, S., and Zhu, Y., 2002, Quantitative reconstruction of lake water paleotemperature of Dahai Lake, Inner Mongolia, China and its significance in paleo-climate. Science in China (Series D), v. 49, pp. 792-800

Soligo, M., Tuccimei, P., Barberi, R., Delitala, M.C., Miccadei, E., and Taddeucci, A., 2002, U/Th dating of freshwater travertine from Middle Velino Valley (Central Italy): paleoclimatic and geological implications. Palaeogeography, Palaeoclimatology, Palaeoecology, v. 184, pp. 147-161.

Vermoere, M., Degryse, P., Vanhecke, L., Muchez, P., Paulissen, E., Smets, E., and Waelkens, M., 1999, Pollen analysis of two travertine sections in Basköy (southwestern Turkey): implications for environmental conditions during the early Holocene. Review of Palaeobotany and Palynology, v. 105, pp. 93-110.

Wachter, E., and Hayes, J.M., 1985, Exchange of oxygen isotopes in carbondioxide- phosphoric acid systems. Chemical Geology, v. 52, pp. 365-374

Walter, H., and Lieth, H., 1960-1967, Klimadiagramm-Weltatlas. Gustav Fischer Jena, 8000 stations.

Wang, Y.J., Cheng, H., Edwards, R.L., An, Z.S., Wu, J.Y., Shen, C.-C., and Dorale, J.A., 2001. A high-resolution absolute-dated Late Pleistocene monsoon record from Hulu Cave, China. Science, v. 294, pp. 2345-2348.
Wei, K., and Gasse, F., 1999, Oxygen isotopes in lacustrine carbonates of West Chine revisited: implications for post glacial changes in summer monsoon circulation. Quaternary Science Reviews, v. 18, pp. 1315-1334.

Wünnemann, B., Pachur, H.J., and Zhang, H., 1998, Climatic and environmental changes in the deserts of Inner Mongolia, China, since the Late Pleistocene, in Alsharhan, A.S., Glennie, K.W., Whittle, G.L., and Kendall, C.G.S., eds, Quaternary Deserts and Climatic Change, Rotterdam, Balkema, pp. 381-394.

Zhang, H., Ma, Y., Li, J., Pachur, H.-J., and Wuenneman, B., 1999, The Holocene palaeoclimatic change in southern vicinity of the Tengger Desert. Chinese Science Bulletin, v. 44, pp. 550-556.

Zhang, H., Ma, Y., Wünnemann, B., and Pachur, H.-J., 2000, A Holocene climatic record from arid northwestern China. Palaeogeography, Palaeoclimatology, Palaeoecology, v. 162, pp. 389-401.

Zhang, X., Liu, J., Tian, L., He, Y., and Yao, T., 2004, Variations of $\delta^{18} \mathrm{O}$ in precipitation along vapor transport paths. Advances in Atmospheric Sciences, v. 21, pp. 562-572.

Zhang, X., Nakawo, M., Yao, T., Han, J., and Xie, Z., 2002, Variations of stable isotopic compositions in precipitation on the Tibetan Plateau and its adjacent regions. Science in China (Series D), v. 45, pp. 481-493.

Zhou, S.Z., Chen, F.H., Pan, B.T., Cao, J.X., Li, J.J., and Derbyshire, E., 1991, Environmental change during the Holocene in western China on a millennial timescale. The Holocene, v. 1, pp. 151-156.

Steffen Mischke is professor for palaeoecology and palaeoclimate studies at the Freie Universität Berlin, Germany, and research associate of the Limnological Research Center of the University of Minnesota, USA. He works on palaeoenvironmental reconstructions and its palaeoclimatic implications in Central Asia and the Near East. He is mainly interested in the natural variability of aquatic ecosystems in the late Quaternary, in spatially differing responses of ecosystems to global climate change, and in quantitative reconstructions of limnological parameters such as salinity and water depth.

Chengjun Zhang received his $P h D$ from the Lanzhou Institute of Geology, Chinese Academy of Sciences in 1997. He works at Lanzhou University since 1999. He was engaged as invited scientist at the Freie Universität Berlin (Germany) and Columbia University (USA). His research interests include the reconstruction of past environmental change in the Quaternary using stable isotopes of organic matter and carbonates from lake sediments, and the environmental pollution of lakes.
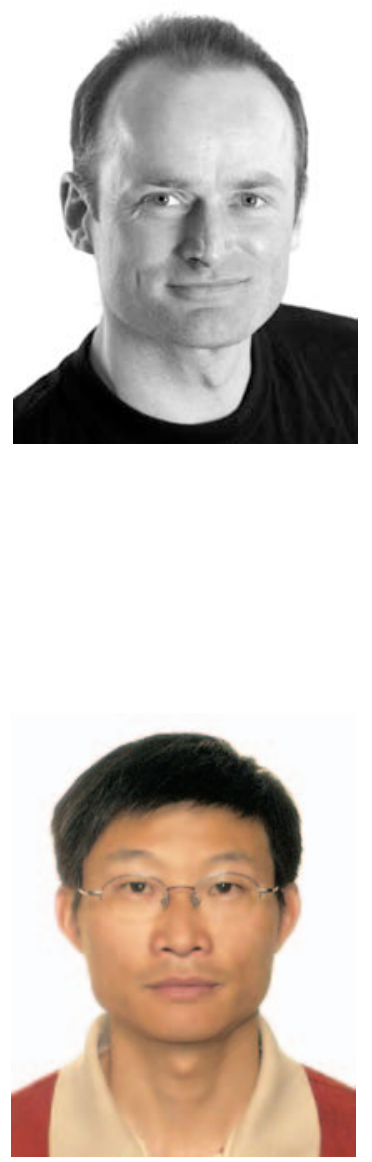